\title{
Reflective writing: a tool to support continuous learning and improved effectiveness in implementation facilitators
}

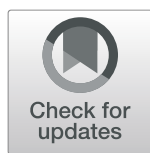

Tanya T. Olmos-Ochoa ${ }^{1 *} \mathbb{D}$, Karissa M. Fenwick', David A. Ganz ${ }^{1,2}$, Neetu Chawla ${ }^{1,3}$, Lauren S. Penney ${ }^{4,5}$, Jenny M. Barnard', Isomi M. Miake-Lye ${ }^{1,3}$, Alison B. Hamilton ${ }^{1,6}$ and Erin P. Finley ${ }^{1,4,5}$

\begin{abstract}
Background: Implementation facilitators support the adoption of evidence-based practices and other improvement efforts in complex healthcare settings. Facilitators are trained to develop essential facilitation skills and facilitator effectiveness is typically evaluated post-implementation, but little is known about how facilitators apply and adapt didactic knowledge after training, or how learning and refining experiential knowledge occurs during the facilitation process. We propose the use of reflective writing as a tool to document and support facilitator learning and facilitator effectiveness.
\end{abstract}

Methods: Using an instrumental case study of the Coordination Toolkit and Coaching (CTAC) project, we explore the use of reflective writing by facilitators to support their learning and effectiveness. Six primary care clinics participated in weekly hour-long facilitation calls over a 12-month period to implement quality improvement projects related to care coordination. Two facilitators completed templated reflections after each facilitation call for their assigned sites, totaling 269 reflections. We used the declarative-procedural-reflective model, which defines the process of skill development in clinical practice, to qualitatively analyze the reflections. Two independent coders used content analysis principles to code text that captured facilitators' observations, evaluations, interpretations, and communication. Descriptive statistics were used to analyze reflections by facilitator and by code within and across reflections.

Results: CTAC facilitators primarily used the reflections to summarize the calls (observation), assess the facilitation process and the tasks and activities they used (evaluation), document their thoughts about how to improve their own effectiveness (interpretation), and describe their communication with implementing teams. Ninety-one percent of reflections included observations, $42 \%$ interpretation, $41 \%$ evaluation, and $44 \%$ facilitator communication. In total, we coded 677 segments of text within reflections: 39\% represented observation, 20\% interpretation, 18\% evaluation, and $23 \%$ facilitator communication.

Conclusions: The process of reflective writing allowed the CTAC facilitators the time and structure to evaluate their facilitation and to think critically about how to adjust their facilitation in response to their observations and interpretations. Reflective writing is a feasible and acceptable tool to support and document facilitator learning and effectiveness.

\footnotetext{
* Correspondence: Tanya.Olmos-Ochoa@va.gov

'HSR\&D Center for the Study of Healthcare Innovation, Implementation and

Policy (CSHIIP), VA Greater Los Angeles Healthcare System - Sepulveda,

16111 Plummer Street (152), North Hills, CA 91343, USA

Full list of author information is available at the end of the article
}

(C) The Author(s). 2021 Open Access This article is licensed under a Creative Commons Attribution 4.0 International License, which permits use, sharing, adaptation, distribution and reproduction in any medium or format, as long as you give appropriate credit to the original author(s) and the source, provide a link to the Creative Commons licence, and indicate if changes were made. The images or other third party material in this article are included in the article's Creative Commons licence, unless indicated otherwise in a credit line to the material. If material is not included in the article's Creative Commons licence and your intended use is not permitted by statutory regulation or exceeds the permitted use, you will need to obtain permission directly from the copyright holder. To view a copy of this licence, visit http://creativecommons.org/licenses/by/4.0/ The Creative Commons Public Domain Dedication waiver (http://creativecommons.org/publicdomain/zero/1.0/) applies to the data made available in this article, unless otherwise stated in a credit line to the data. 
Trial registration: The project was registered with ClinicalTrials.gov (NCT03063294) on February 24, 2017.

Keywords: Implementation facilitation, Facilitator effectiveness, Reflective writing, Quality improvement, Qualitative methods

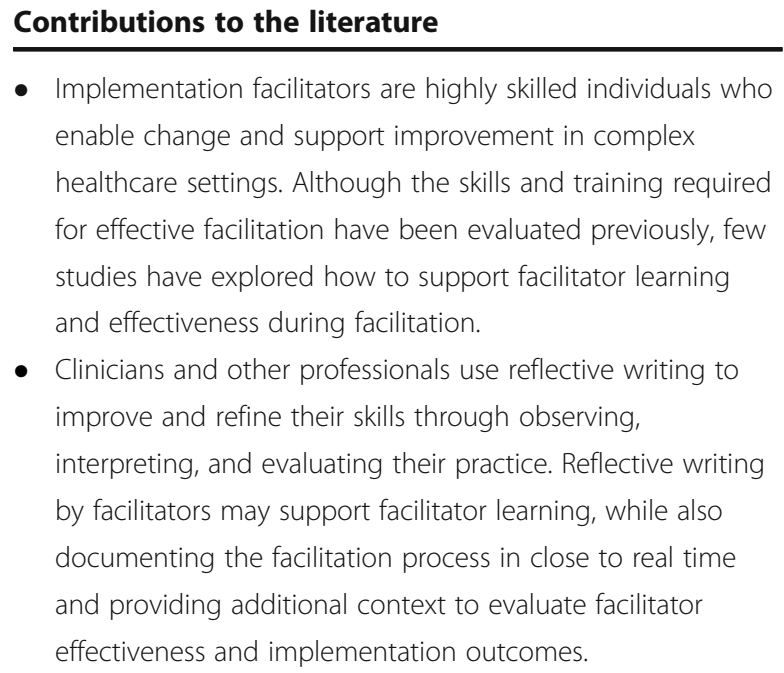

- Implementation facilitators are highly skilled individuals who enable change and support improvement in complex healthcare settings. Although the skills and training required for effective facilitation have been evaluated previously, few studies have explored how to support facilitator learning and effectiveness during facilitation.

- Clinicians and other professionals use reflective writing to improve and refine their skills through observing, interpreting, and evaluating their practice. Reflective writing by facilitators may support facilitator learning, while also documenting the facilitation process in close to real time and providing additional context to evaluate facilitator effectiveness and implementation outcomes.

\section{Background}

Implementation facilitation is an evidence-based implementation strategy used by healthcare organizations and health services researchers to support the adoption of evidence-based practices and to enable quality improvement (QI) [1, 2]. Facilitation, which often requires highintensity interactions with healthcare staff to be successful [1], can be challenging work that entails attending to both the technical (e.g., QI methods) and relational (e.g., interpersonal dynamics) needs of the implementing staff $[3,4]$. The skills needed by facilitators to effectively support implementation and QI efforts are well documented [5-8]. Less is known about whether and how the experience of facilitation impacts facilitator learning and effectiveness during the facilitation process [3, 9].

Reflection, "the process of intentionally focusing one's attention on a particular content; observing and clarifying this focus; and using other knowledge and cognitive process to make meaningful links," [10] has been used to enable learning within clinical and other professions $[11,12]$. The declarative-procedural-reflective (DPR) model used in clinical psychology offers a comprehensive framework illustrating how reflection acts as the "engine" for learning [13], and describes the process of skill development, from didactic learning to its application and refinement in practice. Learners can engage in reflection about their interactions with clients, patients, or colleagues in the context of structured activities like supervision, consultation, and reflective writing $[10,13]$.
Reflective writing is defined as the practice of writing descriptively and analytically about experiences and interactions, including personal reactions and interpretations [13]. The use of reflective writing is a longstanding tradition across a variety of professions. In management, personal and unstructured reflective writing by managers can promote analysis, synthesis, and critical thinking [11]. In psychotherapy training, reflective writing can deepen skill in evidence-based practices [10]. In medical training, reflective writing through structured rubrics and creative writing exercises can improve patient care skills and provider wellbeing [14, 15].

Early evidence suggests that reflection, such as through reflective writing, may promote the development of expertise, reduce stress, prevent burnout, and increase the effectiveness in clinicians $[16,17]$. Despite being distinct practices, both clinical work and implementation facilitation hinge on the application of conceptual skills and knowledge within the context of a structured interpersonal relationship. Therefore, we propose that the benefits of reflective writing seen in other fields, including skill acquisition, may also extend to implementation facilitation. Recent studies have examined how facilitators acquire and retain knowledge from trainings and how key skills are transferred from expert to novice facilitators $[17,18]$. Underexplored is how facilitators adapt and refine their facilitation during the facilitation process and how facilitator effectiveness can be supported and sustained. Documentation of the facilitation process from the facilitator's perspective may provide a more nuanced understanding of facilitator efforts to learn and adapt their facilitation skills and inform strategies to support and evaluate facilitator effectiveness. In this paper, we use an instrumental case study of the Coordination Toolkit and Coaching (CTAC) project in the Veterans Health Administration (VA) to describe the use of reflective writing by implementation facilitators.

\section{Methods}

\section{CTAC initiative outcomes}

CTAC was a QI initiative funded by the VA to improve patients' experience of care coordination in primary care [18-20]. A cluster-randomized design was used to recruit matched pairs of VA primary care clinics assigned to either an active (distance-based facilitation plus online toolkit access) or a passive (online toolkit access only) strategy. Clinics selected locally initiated projects to address their care coordination concerns. Facilitation played a key role in helping clinic sites organize their 
projects to assure clinic-wide implementation, which helped improve intra-clinic communication and created hands-on experiences enabling broader QI skill development for participating staff. In contrast, clinic teams with no facilitator experienced more variable project uptake and skill development was limited to projectspecific knowledge [21].

\section{Study design}

To describe the use of reflective writing by CTAC facilitators and to better contextualize our evaluation findings, we used an instrumental case study design, which focuses more on the issue being researched (use of reflective writing) than on the case from which the issue is analyzed (CTAC) [22-25]. Data were generated by two CTAC facilitators employed to deliver the intervention; both were novice facilitators with doctoral training in health services who had reviewed a facilitation training manual developed for CTAC and shadowed a more experienced facilitator for at least 6 months prior to facilitation of CTAC sites. Each CTAC facilitator was assigned as the primary facilitator for three clinics and was responsible for hosting weekly hour-long facilitation calls with each site over a 12-month project period ( $n=269$ calls across six clinics).

At the start of facilitation, the two CTAC facilitators debriefed verbally with each other about what transpired on the initial facilitation calls; these debriefings proved helpful in thinking about the facilitation process. As a result, the two facilitators began to document and reflect on their facilitation process more consistently, with the goal of improving their facilitation over time. Facilitators logged these reflections using a simple template developed in consultation with the CTAC team, which contained prompts about the facilitation call's date, duration, participants, an open-ended summary of what transpired on the call, and descriptions of facilitation challenges and success experienced on the call. Figure 1 provides an example of a completed facilitation reflection. Thus, in addition to hosting facilitation calls and completing site-related facilitation tasks (e.g., introducing QI methods), CTAC facilitators also completed brief $(<5 \mathrm{~min})$ written reflections after each facilitation call [26].

\section{Conceptual framework}

We used the DPR model to guide our coding and analysis of facilitator reflections $[10,13]$. In the DPR model, skill development and learning occur via three cognitive systems. The declarative system consists of conceptual, technical, and interpersonal knowledge gained from didactic training and study. In the procedural system, declarative knowledge is put into practice during communications with clients. Finally, the reflective system analyzes past, current, or future clinical experiences; compares them with stored information; identifies plans of action; and either maintains or changes stored information as a result of the analysis [13]. Thus, "information is imported into the reflective system from the declarative and procedural systems for analysis and evaluation, prior to re-export back to these systems with plans for action, change, or retention of the status quo." [13]. Reflection is defined as "a metacognitive skill, which encompasses the observation, interpretation, and evaluation of one's own thoughts, emotions and actions, and their outcomes." [10]. Reflection through observation, interpretation, and evaluation requires focused attention on a problem, reconstruction and observation of a situation, elaboration, self-questioning, problem-solving, and imagining of alternatives [10] during and after clinical encounters. Through reflection, individuals can derive perceptual learning, or learning from a "mental representation" of events "to facilitate new understandings" that are then reinforced or debunked when applied in practice to generate new learning [13].

CTAC Facilitation Reflection

Date of Facilitation Call:

Call Duration: (in minutes)

Participants: (Name and Role)

Call Summary:

The call was relatively straightforward today, but it was also a bit challenging. We continued to make progress on the brochure and obtaining staff feedback from both other [QI] team members and other staff who will be attending an upcoming staff meeting. [Name of team member] continued to push for the brochure to represent the [entire] healthcare system [as opposed to just the clinic] and said he [had] "already consulted with" the person who would be implementing this in [the system] as a whole and they were "all onboard." I continue to express hesitation and raise concerns, but not sure what else to say to facilitate the appropriate use of the brochure and use of it at [the clinic] as a pilot site.

Fig. 1 Example of CTAC facilitator reflection 


\section{Data analysis}

We conducted a retrospective qualitative analysis of CTAC facilitators' use of reflective writing during implementation. To operationalize the DPR model's reflective system in our analysis, we generated three top-level codes representative of the reflection process: observation, evaluation, and interpretation. We defined observation as text in the facilitators' reflections that was descriptive, contextual, and a neutral account of what transpired on the facilitation calls. The evaluation code was used to identify text that provided a general valence of the facilitation call (e.g., productive, challenging) and/ or the facilitators' self-perceived effectiveness, such as through descriptions of whether their facilitation methods were successful/unsuccessful. The interpretation code represented facilitators' analyses of why events transpired as they did, along with the facilitators' theories about how to refine their facilitation as a result of their analyses, which suggests perceptual learning or efforts to learn. Facilitators also provided examples of implementation tasks and activities that enabled them to support clinic sites (e.g., discussions related to the project timeline, providing QI methods support). We created an additional code, facilitator communication, to capture these tasks and activities and organize them into sub-categories in our results.

Two independent coders iteratively generated a codebook and used content analysis principles to code facilitator reflections in ATLAS.ti (version 8, GmbH, Berlin), resolving discrepancies in code application through weekly discussions to reach consensus [27, 28]. Codes were applied to complete sentences and spanned multiple sentences as needed to capture each theme occurrence. Within reflections, each code could be used more than once to capture multiple occurrences of observation, evaluation, interpretation, and facilitator communication. Following coding, the coders identified general themes and presented them to the broader CTAC team (principal investigator, project manager, project evaluator, CTAC facilitators) for discussion and further refinement $[29,30]$. We used descriptive statistics to analyze reflections by facilitator and by code across sites.

\section{Results}

CTAC facilitators' use of reflective writing varied within and between facilitators, by length (word count), number of reflections completed per site $($ mean $=45)$, and processes logged (observation, interpretation, and evaluation, facilitator communication) (Table 1). These processes were not mutually exclusive, and reflections often contained all four.

\section{Content of facilitator reflections}

The content of facilitator reflections (Fig. 2) typically started with observations that provided useful context for the facilitators' evaluations and interpretations of the facilitation call. Observations primarily summarized the call, including descriptions of call attendance, project progress and updates, decisions made, and team dynamics. Evaluations generally focused on the perceived valence of the call (e.g., productive, challenging), facilitators' assessment of the effectiveness of facilitation strategies used to address project goals, and the affective (e.g., mental, emotional) impact of the facilitation process on the facilitator.

Text coded as interpretation revealed the most about the facilitators' perceptual learning and efforts to learn by documenting adaptations facilitators tested and made to their facilitation during each facilitation call. In their interpretations, facilitators reflected about their facilitation successes and challenges, including factors related to team dynamics, resistance to change, lack of participation or engagement, and project progress. Facilitators also wrote about future strategies to overcome challenges and enable success by weighing possible next steps in their facilitation. In their reflections about the facilitation process, facilitators considered the clinic environment and its impact on project progress, the implementation site's response to QI methods and tools, and the site's enthusiasm and engagement vis-à-vis project progress.

Descriptions of facilitators' communication with the implementation team (Fig. 3) often occurred alongside examples of reflective interpretation and evaluation, suggesting that communication style was a frequent source of reflection, adaptation, and learning for facilitators. Facilitators communicated with sites about managing the project timeline and adjusting project expectations and suggested alternatives to elements that did not work or were outside the scope of the project. They also offered QI and implementation resources to facilitate project progress and the completion of project deliverables. Generating and maintaining enthusiasm and engagement for the project made up a significant part of the facilitators' communication-related reflections, including

Table 1 Code occurrence by reflections and coded text segments

\begin{tabular}{|c|c|c|c|c|c|}
\hline & Observation code & Interpretation code & Evaluation code & $\begin{array}{l}\text { Facilitator } \\
\text { communication code }\end{array}$ & $\begin{array}{l}\text { Total across } \\
\text { all reflections }\end{array}$ \\
\hline $\begin{array}{l}\text { Number (\%) of reflections including } \geq 1 \\
\text { occurrence of specified code }\end{array}$ & $244(90.7)$ & $113(42.0)$ & $109(40.5)$ & $119(44.2)$ & $269(100.0)$ \\
\hline Number (\%) of coded text segments & $265(39.1)$ & $136(20.0)$ & $123(18.2)$ & $153(22.6)$ & $677(100.0)$ \\
\hline
\end{tabular}




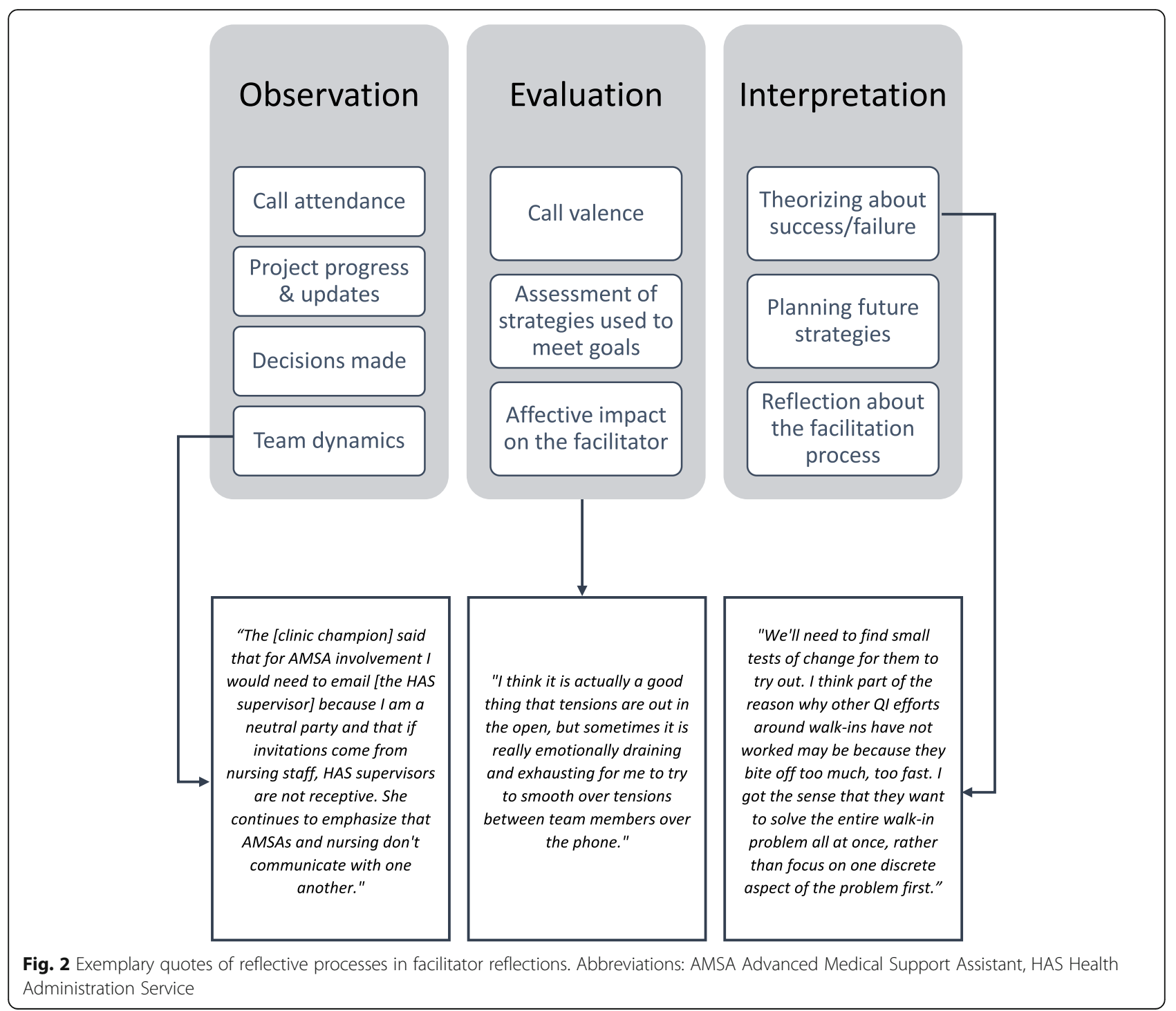

maintaining momentum, encouraging attendance and verbal participation on calls, and fostering effective team communication. Facilitators also communicated with teams to create buy-in for data collection, manage team dynamics, navigate project setbacks, guide effective communication with leadership and other key stakeholders, and discuss project sustainability and spread. Additional file 1 contains exemplary quotes.

\section{Discussion}

The process of reflection through writing allowed CTAC facilitators the time and structure to evaluate their role, to adjust their facilitation in response to their observations and interpretations, and to process the affective impact of facilitation. Reflections included observations of what transpired on the facilitation calls, evaluations of the facilitation process including facilitators' selfperceived effectiveness, interpretations of the facilitation process including facilitators' perceptual learning and efforts to learn, and descriptions of the facilitators' communication.

To our knowledge, this study is the first to explore the use of reflective writing by facilitators during implementation. Existing facilitation studies report on facilitators' characteristics and skills and on activities used by facilitators during facilitation [6-8]. However, few studies have reported on facilitators' experiences of the facilitation process $[9,31,32]$. Reflective writing may help to capture examples of facilitator learning and selfperceived effectiveness by documenting facilitators' application of basic didactic knowledge, perceptual learning, and the incremental development of facilitation expertise [15]. Reflective writing also enabled facilitators to continuously evaluate their facilitation process, identify areas for improvement, and support their learning and effectiveness. Reflecting via writing produced a 


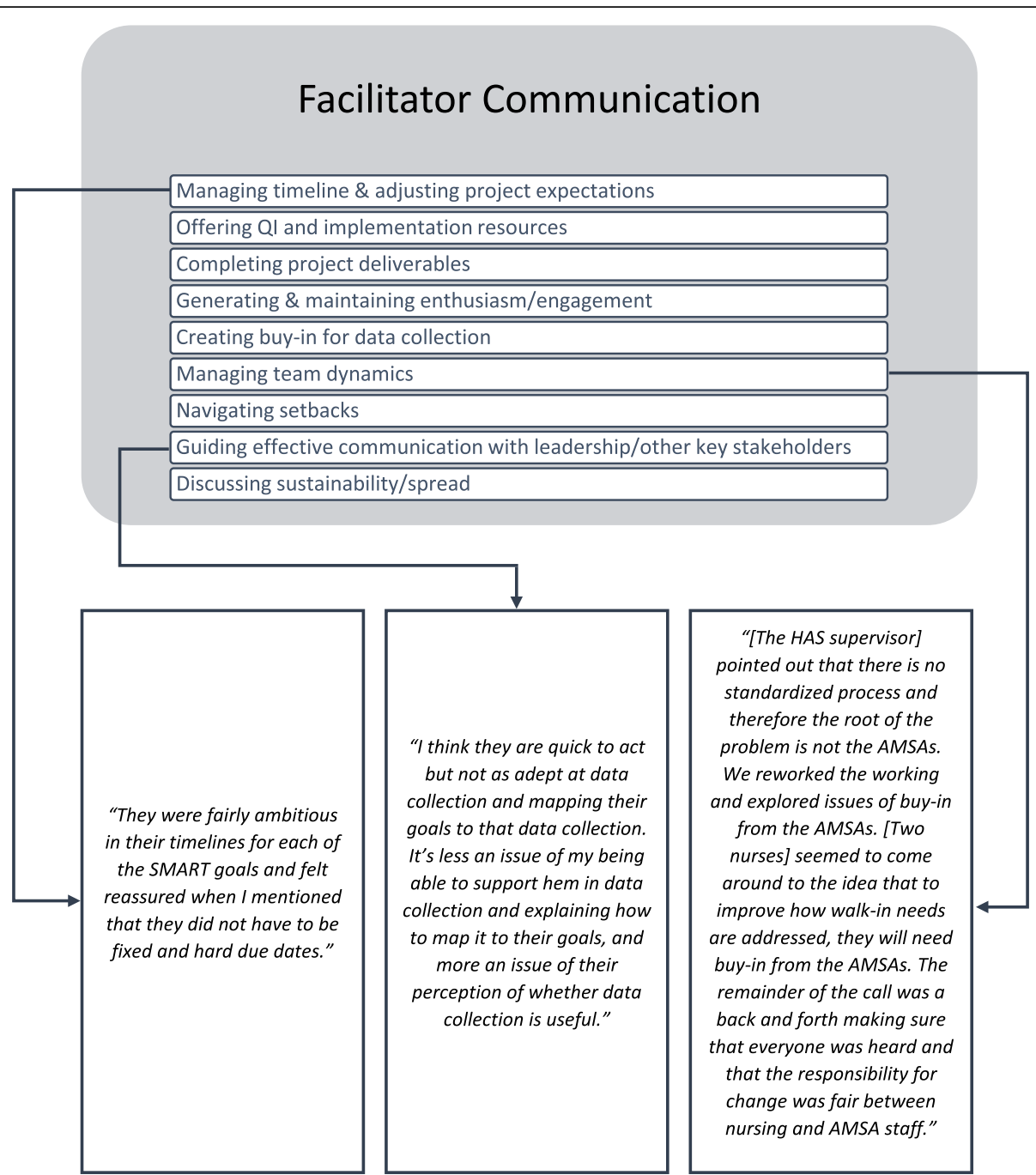

Fig. 3 Exemplary quotes of facilitator communication in facilitator reflections. Abbreviations: AMSA Advanced Medical Support Assistant, HAS Health Administration Service, SMART Specific, Measurable, Achievable, Relevant, and Time-Bound

record of facilitation activities that facilitators could later consult to recall facilitation activities and discussions. It is unclear whether reflective writing offered other unique benefits compared to alternative forms of reflection (e.g., supervision/mentoring, recordings); more work is needed to compare the potential impact of different forms of reflection on facilitator learning. Based on results, we developed and refined a sample reflective writing template with prompts designed to encourage facilitators to reflect on and document their facilitation efforts (Additional file 2).

Written reflections also provided the CTAC team and external evaluators with context to better understand the mixed-methods outcomes of the CTAC initiative [33]. For example, external evaluators reviewed the written reflections to better understand how implementing teams addressed critical junctures in the implementation process (e.g., failure/obstacles to implementation) from the facilitators' perspectives. The reflections were helpful in providing additional context to explain trial results, assessing fidelity and adaptations to the facilitation process, documenting facilitators' perspectives on successes and challenges to implementation, and aiding facilitator recall during weekly updates to the CTAC team. Our findings align with others suggesting that regular check-ins during implementation may improve documentation of and engagement in implementation activities [34]. Additional research is needed to assess the potential of facilitator reflections as a novel data source to evaluate facilitation and implementation outcomes.

There were several study limitations that should be considered. The CTAC reflective writing template was open-ended and relatively brief, potentially limiting the extent to which facilitators described thoughts and activities. Nonetheless, these data were rich in detail and offered insight into how facilitators reflect when given 
minimal prompting. CTAC facilitators were novice facilitators who chose to complete reflections; we were therefore unable to assess whether and how facilitators with different levels of training or expertise may use reflective writing differently. Furthermore, data were limited to reflections from only two facilitators, the total employed for the project. Nonetheless, the high facilitation intensity (weekly, 1-h calls over 12 months) and multiple study sites in this project resulted in a large number of written reflections that captured variations in content within and across reflections and facilitators. CTAC facilitation took place in the context of a funded QI project, and facilitators had protected time to complete their reflections ( $<5 \mathrm{~min}$ each to complete). Facilitators with higher caseloads and/or a lack of protected time may have more difficulty completing reflective writing. Finally, we did not empirically measure the relationship between reflective writing and facilitator outcomes, although the two facilitators in this study anecdotally reported that reflective writing improved their wellbeing and practice. Additional work assessing the use of templated reflections with larger facilitator samples and varying levels of facilitator expertise may address some of these limitations. Work to explore reflective writing across different facilitation settings, and in both internal and external facilitation contexts, is also needed.

\section{Conclusion}

Two facilitators, given protected time, found reflective writing to be a feasible and acceptable tool that enabled them to document their observations, interpretations, evaluations, and communication during the facilitation process. Reflective writing provided facilitators a means by which to attend to opportunities for learning and improving their effectiveness as facilitators, while also providing an important source of real-time qualitative data on implementation progress and activities. Reflective writing by facilitators may also have potential for informing the broader study of fidelity to and outcomes in implementation facilitation.

\section{Abbreviations \\ CTAC: Coordination Toolkit and Coaching; Ql: Quality improvement; DPR: Declarative-procedural-reflective; VA: Veterans Health Administration; AMSA: Advanced Medical Support Assistant; HAS: Health Administration Service; RN: Registered nurse; SMART: Specific, Measurable, Achievable, Relevant, and Time-Bound}

\section{Supplementary Information}

The online version contains supplementary material available at https://doi. org/10.1186/s43058-021-00203-z.

Additional file 1.

\section{Additional file 2}

\section{Acknowledgements}

We want to acknowledge and thank Lisa Rubenstein for co-conceiving CTAC and Debbie Delevan for the administrative support she provided on the project. We thank Polly H. Noël, Danielle E. Rose, Alissa Simon, and Susan E. Stockdale for their valuable contributions to the CTAC project.

\section{Source of support}

This material is based upon work supported by the Department of Veterans Affairs, Quality Enhancement Research Initiative through a grant to the Care Coordination QUERI Program (QUE 15-276). The views expressed in this article are those of the authors and do not necessarily reflect the position or policy of the Department of Veterans Affairs or the US government.

\section{Authors' contributions}

DAG (principal investigator) conceived the project, acquired funding, and contributed to the manuscript. TTO and KF led the development of the manuscript, and EPF contributed to the manuscript and provided guidance regarding framing and theory. $\mathrm{LP}, \mathrm{NC}, \mathrm{IM}$, and $\mathrm{ABH}$ contributed to and reviewed the manuscript. JB coordinated the project and contributed to the manuscript. All authors read and approved the final manuscript. None of the coauthors has competing interests.

\section{Funding}

This project was funded by the Veterans Affairs, Quality Enhancement Research Initiative (QUERI) through a grant to the Care Coordination QUERI Program (QUE 15-276). The views expressed in this article are those of the authors and do not necessarily reflect the position or policy of the Department of Veterans Affairs or the US government.

\section{Availability of data and materials}

Consents associated with primary data collection for clinician/staff participants in CTAC did not include permission to share data in publicly available repositories. De-identified administrative datasets may be eligible for future data sharing once national VA guidance on request and distribution processes are provided (in process). Final datasets will be maintained locally until enterprise-level resources become available for long-term storage and access.

\section{Declarations}

Ethics approval and consent to participate

This project was supported by the VA Quality Enhancement Research Initiative (QUERI). VA Central Office and the IRB at VA Greater Los Angeles Healthcare System designated and approved the project as non-research. Process data collected by the facilitators were collected as part of the quality improvement project and do not identify individual participants in the project. As non-research, participants were not formally consented, but they were also not mandated to participate and could opt out from participating. Their consent was implied through their participation in the project.

Consent for publication

No individual person's data in any form are included in this manuscript.

\section{Competing interests}

The authors declare that they have no competing interests.

\section{Author details}

${ }^{1} H S R \& D$ Center for the Study of Healthcare Innovation, Implementation and Policy (CSHIIP), VA Greater Los Angeles Healthcare System - Sepulveda, 16111 Plummer Street (152), North Hills, CA 91343, USA. ${ }^{2}$ David Geffen School of Medicine, University of California at Los Angeles, Los Angeles, CA, USA. ${ }^{3}$ Department of Health Policy and Management, Fielding School of Public Health, University of California at Los Angeles, Los Angeles, CA, USA. ${ }^{4}$ Elizabeth Dole Center of Excellence for Veteran and Caregiver Research, South Texas Veterans Health Care System, San Antonio, TX, USA.

${ }^{5}$ Departments of Medicine and Psychiatry, University of Texas Health Science Center at San Antonio, San Antonio, TX, USA. ${ }^{6}$ Department of Psychiatry and 
Biobehavioral Sciences, David Geffen School of Medicine, University of California at Los Angeles, Los Angeles, CA, USA.

\section{Received: 1 March 2021 Accepted: 25 August 2021} Published online: 03 September 2021

\section{References}

1. Baskerville NB, Liddy C, Hogg W. Systematic review and meta-analysis of practice facilitation within primary care settings. Ann Fam Med. 2012;10(1): 63-74. https://doi.org/10.1370/afm.1312.

2. Berta W, Cranley L, Dearing JW, Dogherty EJ, Squires JE, Estabrooks CA. Why (we think) facilitation works: insights from organizational learning theory. Implement Sci. 2015;10(1):141. https://doi.org/10.1186/ s13012-015-0323-0.

3. Olmos-Ochoa TT, Ganz DA, Barnard JM, Penney LS, Chawla N. Sustaining effective quality improvement: building capacity for resilience in the practice facilitator workforce. BMJ Qual Saf. 2019;28(12):1016-20. https://doi. org/10.1136/bmjqs-2019-009950.

4. Gunderson LM, Willging CE, Trott Jaramillo EM, Green AE, Fettes DL, Hect $D B$, et al. The good coach: implementation and sustainment factors that affect coaching as evidence-based intervention fidelity support. J Child Serv. 2018;13(1):1-17. https://doi.org/10.1108/JCS-09-2017-0043.

5. Harvey G, Kitson A. Implementing evidence-based practice in healthcare: a facilitation guide. New York: Routledge; 2015. https://doi.org/10.4324/97802 03557334.

6. Kitson AL, Harvey G. Methods to succeed in effective knowledge translation in clinical practice. J Nurs Scholarsh. 2016;48(3):294-302. https://doi.org/1 $0.1111 /$ jnu. 12206.

7. Rycroft-Malone J, Seers K, Eldh AC, Cox K, Crichton N, Harvey G, et al. A realist process evaluation within the Facilitating Implementation of Research Evidence (FIRE) cluster randomised controlled international trial: an exemplar. Implement Sci. 2018;13(1):138. https://doi.org/10.1186/s13012-01 8-0811-0.

8. Harvey G, McCormack B, Kitson A, Lynch E, Titchen A. Designing and implementing two facilitation interventions within the 'Facilitating Implementation of Research Evidence (FIRE)' study: a qualitative analysis from an external facilitators' perspective. Implement Sci. 2018;13(1):141. https://doi.org/10.1186/s13012-018-0812-z.

9. Olmos-Ochoa TT, Ganz DA, Barnard JM, Penney L, Finley EP, Hamilton AB, et al. Sustaining implementation facilitation: a model for facilitator resilience. Implement Sci Commun. 2021;2(1):65. https://doi.org/10.1186/s43058-02100171-4.

10. Bennett-Levy JT,R; Chaddock, A; Davis, M. Reflective practice in cognitive behavioural therapy: the engine of lifelong learning. In: Stedmon JD, R, editor. Reflective practice in psychotherapy and counselling. Berkshire: Open University Press; 2009. p. 115-135.

11. Gray DE. Facilitating management learning: developing critical reflection through reflective tools. Manag Learn. 2007;38(5):495-517. https://doi.org/1 $0.1177 / 1350507607083204$

12. Uline C, Wilson JD, Cordry S. Reflective journals: a valuable tool for teacher preparation. Education. 2004;124(3):456-60.

13. Bennett-Levy J. Therapist skills: a cognitive model of their acquisition and refinement. Behav Cogn Psychother. 2006;34(1):57-78. https://doi.org/10.101 7/S1352465805002420

14. Wald HS, Borkan JM, Taylor JS, Anthony D, Reis SP. Fostering and evaluating reflective capacity in medical education: developing the REFLECT rubric for assessing reflective writing. Acad Med. 2012;87(1):41-50. https://doi.org/10.1 097/ACM.0b013e31823b55fa.

15. Wald HS, Reis SP. Beyond the margins: reflective writing and development of reflective capacity in medical education. J Gen Intern Med. 2010;25(7): 746-9. https://doi.org/10.1007/s11606-010-1347-4.

16. Hazen KP, Carlson MW, Hatton-Bowers H, Fessinger MB, Cole-Mossman J, Bahm J, et al. Evaluating the facilitating attuned interactions (FAN) approach: vicarious trauma, professional burnout, and reflective practice. Child Youth Serv Rev. 2020;112:104925. https://doi.org/10.1016/j.childyouth.2 020.104925 .

17. Lutz G, Scheffer C, Edelhaeuser F, Tauschel D, Neumann M. A reflective practice intervention for professional development, reduced stress and improved patient care--a qualitative developmental evaluation. Patient Educ Couns. 2013;92(3):337-45. https://doi.org/10.1016/j.pec.2013.03.020.
18. Ganz DA, Barnard JM, Smith NZY, Miake-Lye IM, Delevan DM, Simon A, et al. Development of a web-based toolkit to support improvement of care coordination in primary care. Transl Behav Med. 2018;8(3):492-502. https:// doi.org/10.1093/tbm/ibx072.

19. Noel PH, Barnard JM, Leng M, Penney LS, Bharath PS, Olmos-Ochoa TT, et al. The coordination toolkit and coaching project: cluster-randomized quality improvement initiative to improve patient experience of care coordination. J Gen Intern Med. 2021. https://doi.org/10.1007/s11606021-06926-y.

20. Olmos-Ochoa TT, Bharath P, Ganz DA, Noel PH, Chawla N, Barnard JM, et al. Staff perspectives on primary care teams as de facto "hubs" for care coordination in VA: a qualitative study. J Gen Intern Med. 2019;34(Suppl 1): 82-9. https://doi.org/10.1007/s11606-019-04967-y.

21. Ganz DNN, Penney L, Olmos-Ochoa $\Pi$, Chawla N. The influence of facilitation on care coordination in VA primary care: evaluation of the CTAC quality improvement project: VA Health Services \& Research Development; 2020.

22. Crowe S, Cresswell K, Robertson A, Huby G, Avery A, Sheikh A. The case study approach. BMC Med Res Methodol. 2011;11(1):100. https://doi.org/1 0.1186/1471-2288-11-100.

23. Stake R. The art of case study research. London: Sage Publications Ltd; 1995.

24. Yazan B. Three approaches to case study methods in education: Yin, Merriam, and Stake. Qual Rep. 2015;20(2):134-52.

25. Yin R. Case study research: design and methods. 4th ed. Thousand Oaks: Sage; 2009.

26. Finley EP, Huynh AK, Farmer MM, Bean-Mayberry B, Moin T, Oishi SM, et al. Periodic reflections: a method of guided discussions for documenting implementation phenomena. BMC Med Res Methodol. 2018;18(1):153. https://doi.org/10.1186/s12874-018-0610-y.

27. Charmaz K. Constructing grounded theory: a practical guide through qualitative analysis. Thousand Oaks: Sage Publications, Inc.; 2014.

28. Miles MBH, A.M, Saldana J. Qualitative data analysis: an expanded sourcebook. 2nd ed. Thousand Oaks: Sage Publications; 2019.

29. Cole FL. Content analysis: process and application. 1988;2(1):53-7.

30. Watkins DC. Rapid and rigorous qualitative data analysis: the "RADaR" technique for applied research. Int J Qual Methods. 2017;16(1): 1609406917712131.

31. Olmos-Ochoa TT, Ganz DA, Barnard JM, Penney LS, Chawla N. Sustaining effective quality improvement: building capacity for resilience in the practice facilitator workforce. BMJ Qual Saf. 2019:bmjqs-2019-009950. https://doi.org/10.1136/bmjqs-2019-009950.

32. Ritchie MJ, Parker LE, Kirchner JE. From novice to expert: a qualitative study of implementation facilitation skills. Implement Sci Commun. 2020;1(1):25. https://doi.org/10.1186/s43058-020-00006-8.

33. Lauren S, Penney Purnima S, Bharath Isomi B, Miake-Lye Mei, Leng Tanya T, Olmos-Ochoa Erin P, Finley Neetu, Chawla Jenny M, Barnard David A, Ganz. Toolkit and distance coaching strategies: a mixed methods evaluation of a trial to implement care coordination quality improvement projects in primary care. BMC Health Services Research. 2021;21(1). https://doi.org/10.11 86/s12913-021-06850-1.

34. Gruß I, Bunce A, Davis J, Gold R. Unintended consequences: a qualitative study exploring the impact of collecting implementation process data with phone interviews on implementation activities. Implementation Sci Commun. 2020;1(1):101. https://doi.org/10.1186/s43058-020-00093-7.

\section{Publisher's Note}

Springer Nature remains neutral with regard to jurisdictional claims in published maps and institutional affiliations. 